\title{
Investigation of carbon contamination in lost foam castings of low carbon steel
}

Oznur Kilic, *Serhat Acar, Alptekin Kisasoz, and Kerem Altug Guler

Department of Metallurgical and Materials Engineering, Yildiz Technical University, Istanbul, Turkey

\begin{abstract}
Lost foam casting (LFC) process is a special casting method in which polymeric foam patterns with refractory coatings are utilized as a mould component. In this work, four types of foam: expandable polyethylene (EPE), expandable polypropylene (EPP) and expandable polystyrene (EPS) foams with two different densities were employed as pattern materials. LFC and conventional green sand mould casting methods were used to cast a low carbon steel, A216 Grade WCB. Both casting processes were carried out at $1,580{ }^{\circ} \mathrm{C}$. Chemical analysis results showed that the carbon contamination level was high and was influenced by pattern type. Metallographic investigations revealed a significant increase in the percentage of pearlite phase in all LFC samples. Densities of manufactured samples were calculated in order to evaluate porosity of the products. It was determined that the densities of the LFC samples were lower than the green sand mould cast reference sample (RS). Vickers hardness tests were also carried out and increments in hardness values with increased carbon content was observed.
\end{abstract}

Key words: lost foam casting (LFC); EPS pattern; EPE pattern; EPP pattern; carbon contamination; A216 Grade WCB

CLC numbers: TG249.5 Document code: A

Article ID: 1672-6421(2018 05-384-06

$\mathrm{L}$ ost foam casting (LFC), also known as full mould casting, was invented and patented by Shoyer in $1958^{[1-3]}$. LFC is evaluated as a new casting method to obtain near net shaped products which is carried out with expendable patterns produced from polymeric materials ${ }^{[4,5]}$. In order to prepare a mould for LFC process, the polymeric pattern is coated with water-based refractory slurry, then placed in a flask, and finally the rest of the flask is filled with unbonded (loose) sand with the help of vibration to compress the sand. After the mould is prepared, the molten metal is poured directly onto the pattern ${ }^{[5,6]}$. At the end of process, the foam polymer undergoes thermal degradation with high heat input and the liquid metal takes the solid pattern's place. Subsequent to solidification, a cast product with high dimensional accuracy is obtained ${ }^{[5,7]}$.

The LFC process is applied to produce engine components, intake manifolds, brake pump housings, etc.

\footnotetext{
*Oznur Kilic

Female, born in 1995. She has been employed as a quality control engineer at Akmetal Metallurgy Industries Corp. since April, 2017. Her academic studies are focused on lost foam casting and the effects of orbital shaking during casting process.

${ }^{*}$ Corresponding author: Serhat Acar

E-mail: seacar@yildiz.edu.tr
}

Received: 2018-07-19; Accepted: 2018-08-25
To date, studies have shown that the LFC process has attractive aspects for both ferrous and non-ferrous alloys, especially aluminium, magnesium, steel and cast iron ${ }^{[3,8]}$.

LFC process has many advantages over conventional casting methods. Particularly, there is no need to use cores to produce parts with a complex geometry , and utilizing foam patterns yields close dimensional tolerance, no separation line, and also good surface quality. In addition to these, reusability of sand provides low processing costs, and helps this method to become more environment friendly ${ }^{[9-11]}$. Despite these advantages, the method has several disadvantages such as carbon defects, coarser grain morphology because of relatively higher casting temperatures, insufficient coating of pattern material which may lead to liquid metal penetration, pinholes and shrinkage defects may occur on the cast product ${ }^{[12,13]}$. In order to avoid the problems mentioned above, many different parameters must be taken into account during the whole process. These include: type and density of pattern materials, type of the sand, quality and thickness of the refractory coating, pouring temperature, and pouring rate ${ }^{[14]}$.

The most dominant and widespread polymeric pattern material in the LFC process is expandable polystyrene (EPS) ${ }^{[15]}$. However, using polystyrene pattern for casting of ferrous alloys causes major carbon defects ${ }^{[7]}$. The polymer begins to decompose when liquid metal, which 
is with very high temperature, contacts the pattern. When the temperature reaches around $500{ }^{\circ} \mathrm{C}$, styrene decomposes to $\mathrm{C}_{8} \mathrm{H}_{8}$ monomers. As the temperature increases further, the monomer molecules decompose into lighter hydrocarbons such as $\mathrm{C}_{7} \mathrm{H}_{8}$, $\mathrm{C}_{6} \mathrm{H}_{6}, \mathrm{C}_{2} \mathrm{H}_{4}$ and $\mathrm{C}_{2} \mathrm{H}_{2}$. This widespread problem can be solved by using other polymers or copolymers ${ }^{[14-16]}$.

In this study, four different types of foam patterns, expandable polyethylene (EPE), EPS with two different densities, and expandable polypropylene (EPP) were used as pattern materials for the LFC process of low carbon steel A216 Grade WCB. The main aim was to determine the effects of carbon contamination for different pattern types on the final cast product's chemical composition, microstructure, and hardness properties.

\section{Experimental}

Polymeric patterns $(100 \mathrm{~mm} \times 40 \mathrm{~mm} \times 35 \mathrm{~mm}$ approx. $)$ with different densities were combined with pouring basin parts $(26$ $\mathrm{mm} \times 52 \mathrm{~mm} \times 46 \mathrm{~mm}$ approx.) using thermoplastic pattern adhesive. Afterward, foam patterns were dipped into commercial water-based refractory slurry (ASK Chemicals Polytop FS 6) for coating in order to avoid sand erosion during the casting process, and dried out for $24 \mathrm{~h}$ at room conditions. Utilized pattern materials and their calculated densities are given in Table 1. Density measurements were carried out via Precisa density. The combined pattern parts also can be seen in Fig. 1.

Table 1: Measured densities for different pattern materials

\begin{tabular}{|cc|}
\hline Foam Type & Density $\left(\mathbf{k g} \cdot \mathbf{m}^{-3}\right.$ ) \\
\hline Expandable polystyrene 1 (EPS-1) & 10.90 \\
Expandable polystyrene 2 (EPS-2) & 23.24 \\
Expandable polyethylene (EPE) & 35.60 \\
Expandable polypropylene (EPP) & 22.44
\end{tabular}
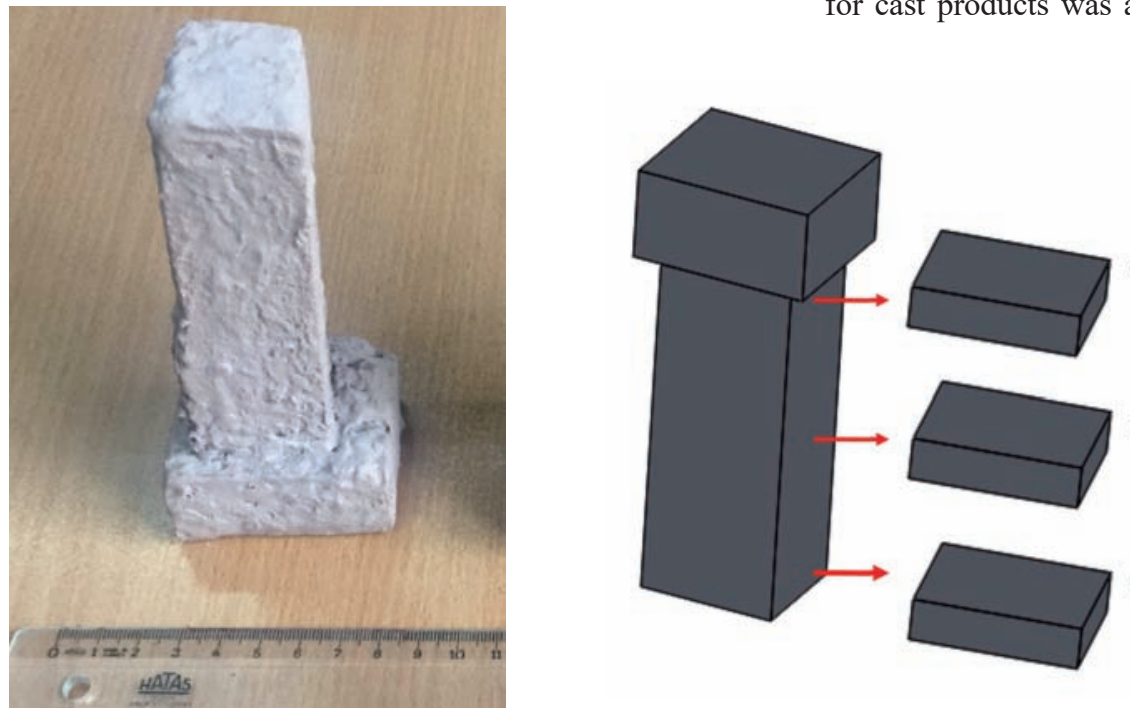

- Chemical analysis, hardness test, density measurement

- Chemical analysis, hardness test, density measurement

Fig. 1: Combined, coated and dried pattern parts

Fig. 3: Sampling positions for characterization steps
Flasks which were used for mould making were filled with loose dry silica sand (40-47 AFS) to a certain height from the bottom. Then the patterns were placed and the flask was totally filled with loose dry silica sand. A demonstration for a prepared mould is given in Fig. 2.

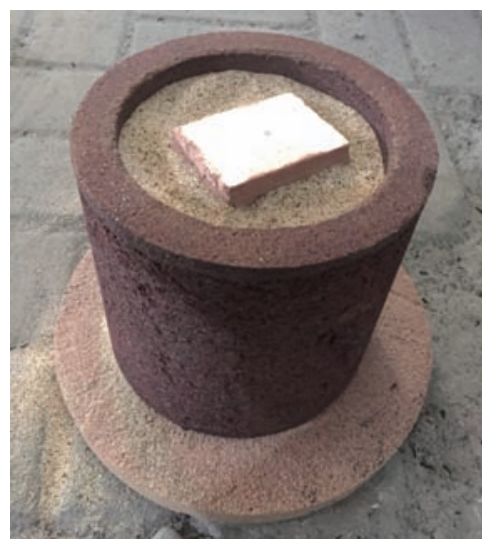

Fig. 2: Prepared mould for casting process

A low carbon steel (A216 Grade WCB) was melted in an induction furnace and cast at $1,580{ }^{\circ} \mathrm{C}$. Chemical composition of the liquid metal is given in Table 2 . In order to evaluate the effects of different pattern types on the final cast product's various properties, a reference sample (RS) was produced by green sand mould casting at the same temperature. After solidification, specimens were removed from the mould and cut from three different zones as given in Fig. 3 for characterization steps. All samples (RS and LFC samples) were subjected to chemical analysis with optical emission spectrometer (Oxford Instruments Foundry-Master Pro) in order to investigate whether any change occurred in composition between different cast products or different parts for each specimen. Chemical analyses were repeated for 5 times and average chemical compositions were determined. In order to refine coarse cast microstructure, normalization heat treatment which is a standard procedure for cast products was applied to all specimens. Normalization 
Table 2: Chemical composition of liquid metal (wt.\%)

$\begin{array}{ccccccccc}\mathbf{C} & \mathbf{S i} & \mathbf{M n} & \mathbf{P} & \mathbf{C u} & \mathrm{Ni} & \mathbf{C r} & \mathrm{Mo} & \mathrm{Fe} \\ 0.204 & 0.6 & 0.872 & 0.15 & 0.3 & 0.5 & 0.221 & 0.056 & 97.7\end{array}$

temperatures were determined $40{ }^{\circ} \mathrm{C}$ above calculated $\mathrm{A} 3$ temperature according to carbon equivalent of alloys, and heat treatments were applied at $900{ }^{\circ} \mathrm{C}$ for RS, $880{ }^{\circ} \mathrm{C}$ for EPE and $865^{\circ} \mathrm{C}$ for the other three specimens.

Samples were ground, polished and etched with $2 \%$ nital solution. Metallographic examinations were carried out with Nikon Eclipse MA100 light microscope; pearlite/ferrite ratios and equivalent diameters for porosities were determined with NIS-Elements Br software. Subsequently, densities of specimens were determined by using Archimedes principle with Precisa density kit. Hardness values of the specimens were measured by Brinell hardness method with $2.5 \mathrm{~mm}$ ball diameter and 187.5 kgf load.

\section{Results and discussion}

On the macro scale, castings which were produced in moulds prepared with EPE, EPS-2 and EPP patterns were successful and pattern-metal replacement was achieved without any fault. However, due to the low density of EPS-1, with a density lower than half of other patterns, only small amount of cast product was obtained because of rapid deterioration of the pattern material. Expandable polystyrene with low density was commonly used as a pattern material in LFC process for nonferrous alloys mostly for aluminium. Nevertheless, the material could not bear high heat input of liquid steel and decomposed too rapidly before the casting process was completed. Moreover, application of direct pouring technique onto the pattern was another possible reason for this situation.

Average chemical compositions of RS and LFC samples and chemical requirements for selected alloy are given in Table 3. Chemical analysis results displayed that the amount of carbon in all LFC samples was increased and found 0.291 \pm 0.004 wt.\% for EPE, $0.354 \pm 0.007$ wt. $\%$ for EPS-1, $0.361 \pm 0.008$ wt. $\%$ for

Table 3: Average chemical compositions (wt.\%) of RS, EPS-1, EPS-2, EPE, EPP samples (as-cast state) and chemical requirements for A216 Grade WCB alloy ${ }^{[17]}$.

$\begin{array}{cccccccc}\text { Element } & \text { RS } & \text { EPS-1 } & \text { EPS-2 } & \text { EPE } & \text { EPP } & \begin{array}{c}\text { Chemical req. } \\ \text { (max) }\end{array} \\ \mathrm{C} & 0.214 & 0.354 & 0.361 & 0.291 & 0.384 & 0.30 \\ \mathrm{Si} & 0.458 & 0.459 & 0.437 & 0.453 & 0.469 & 0.6 \\ \mathrm{Mn} & 0.876 & 0.879 & 0.883 & 0.851 & 0.863 & 1.00 \\ \mathrm{P} & 0.017 & 0.019 & 0.017 & 0.017 & 0.017 & 0.035 \\ \mathrm{Cu} & 0.052 & 0.066 & 0.052 & 0.066 & 0.006 & 0.3 \\ \mathrm{Ni} & 0.100 & 0.090 & 0.095 & 0.088 & 0.09 & 0.5 \\ \mathrm{Cr} & 0.207 & 0.199 & 0.200 & 0.194 & 0.196 & 0.5 \\ \mathrm{Mo} & 0.056 & 0.063 & 0.055 & 0.063 & 0.069 & 0.2 \\ \mathrm{Fe} & 97.7 & 97.6 & 97.6 & 97.8 & 97.6 & 97 \text { to } 100\end{array}$

EPS-2, and 0.384 \pm 0.006 wt.\% for EPP while it was measured $0.204 \pm 0.005$ wt. $\%$ for liquid metal and $0.214 \pm 0.003$ wt. $\%$ for RS. According to the results, the cast sample produced with EPP was exposed to the highest carbon pollution among all other cast specimens. The carbon atoms in the propylene main chain are third-degree (tertiary), and they are always open to attack because this configuration polypropylene has a lower thermal stability compared to other foam materials ${ }^{[17]}$. Thus, carbon diffusion into the liquid metal with higher rates was inevitable. Calculated density of EPS-1 pattern was less than half of EPS-2 pattern; however, it caused the same amount of carbon increase in the cast steel alloy. Therefore, it is not sensible to expect a proportional increase in carbon amount in cast metal related with pattern density. EPE was the densest pattern which was used in this study. Nevertheless, it caused less carbon pollution in metal than any other pattern materials caused.

Microstructures taken from as-cast and normalized specimens can be seen in Fig. 4. Microstructures consisted of ferrite and pearlite with different ratios depending on chemical composition. Light coloured areas in the microstructures represent ferrite phase while darker phase is pearlite. Microstructures on the left side belong to as-cast specimens for all casting procedures and microstructures of normalized specimens are located on the right side. Hypoeutectoid steel alloys start to solidify with $\delta$-ferrite but until they reach room temperature, $\delta$-ferrite to $\gamma$-austenite and $\gamma$-austenite to $\alpha$-ferrite phase transformations take place. During the $\gamma-\alpha$ transformation, $\alpha$ nucleates at $\gamma$ grain boundaries and grows throughout these boundaries. This transformation mechanism is common for Fe-Mn-C ternary alloys and the formed $\alpha$ is called allotriomorphic ferrite. According to Fig. 4, 

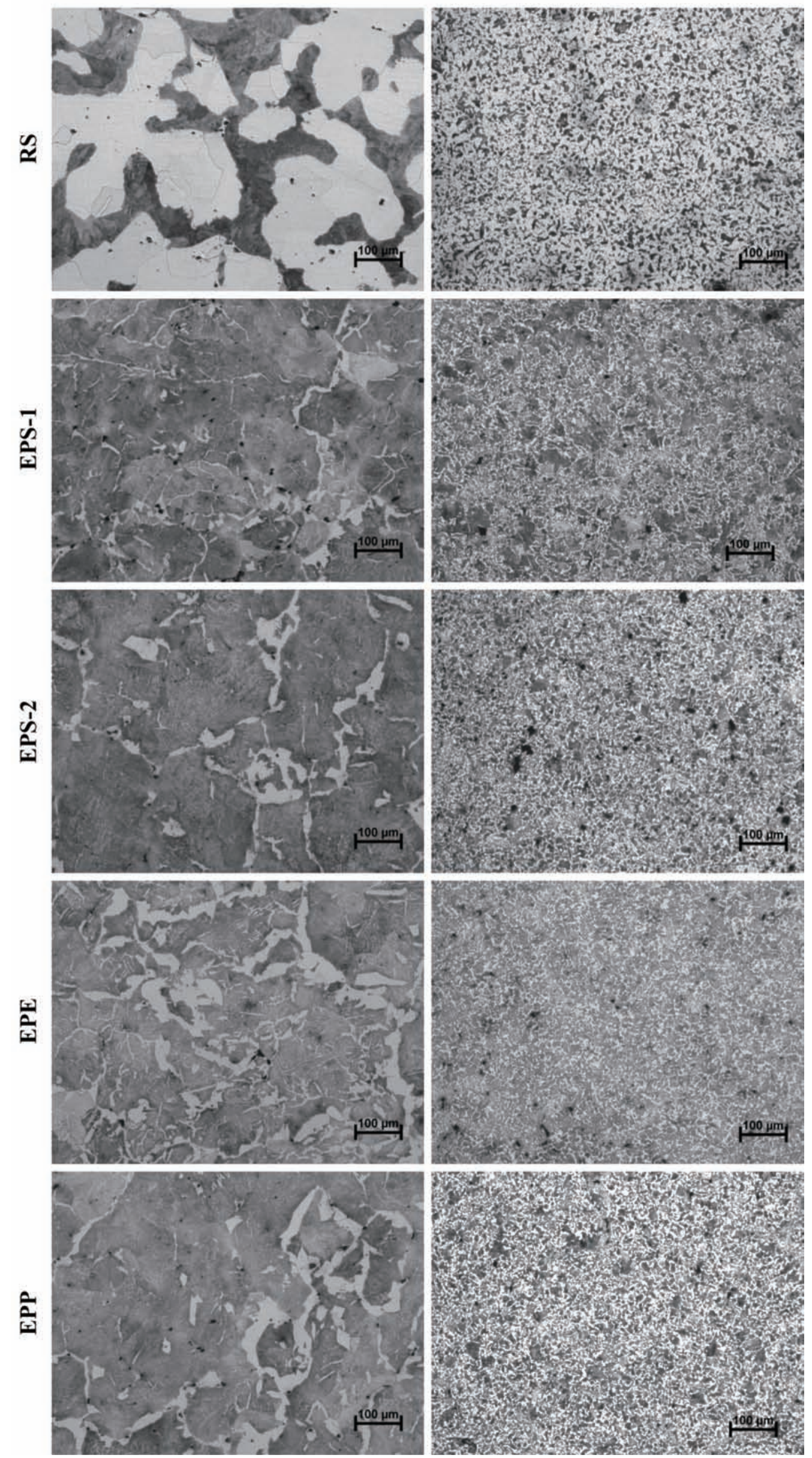

Fig. 4: Microstructures of specimens 
as-cast microstructures comprised of $\alpha$ which nucleated and grew along $\gamma$ grain boundaries. This formation is not suitable in terms of homogeneity in microstructure and grain size; therefore, normalization is essential to cast products. After the normalization procedure, a homogenous ferrite-pearlite structure with fine grains was obtained. Pearlite ratios of normalized specimens are given in Fig. 5. Determined pearlite ratios were found coherent to obtained chemical compositions. Increase in carbon content caused increase in pearlite fraction as expected.

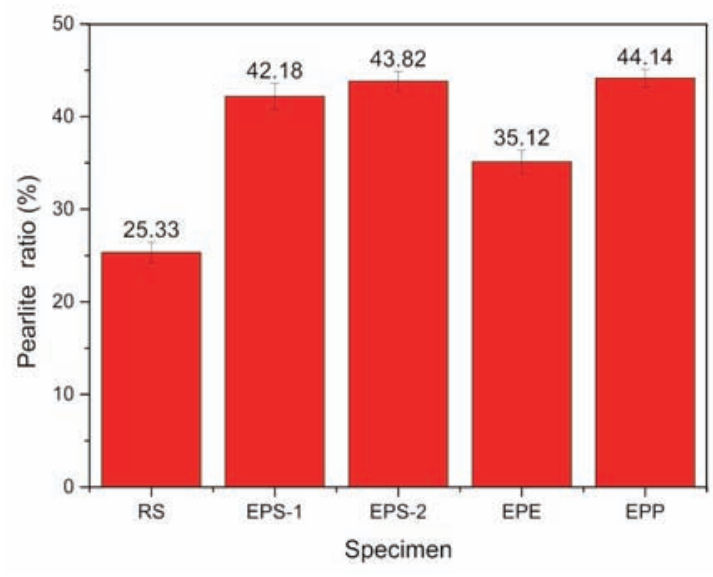

Fig. 5: Pearlite ratio (\%) for all samples

During lost foam casting, high metal velocity may cause turbulence and casting defects. This is caused by the trapping of dissolution products of foam pattern, which occurred during contact with the liquid metal ${ }^{[18]}$. The porosity areas are shown in Fig. 6 with enlarged magnification for the EPP sample. Micro porosities were observed in all samples cast by LFC method.

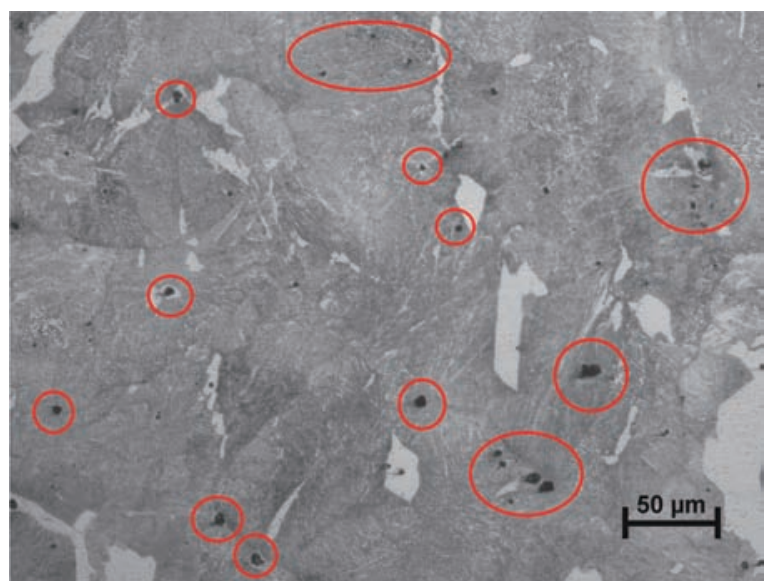

Fig. 6: Microporosity areas in EPP sample

Densities of cast metals were calculated with Archimedes principle in order to evaluate effects of pattern type on cast product's physical properties. As shown in Table 4, densities of samples cast with LFC method were found lower than those of green sand mould cast RS. The existence of casting defects with increased amount compared to RS was the main reason for that decrement in density for LFC samples.
Table 4: Density calculations of all samples

$\begin{array}{cc}\text { Sample } & \text { Density }\left(\mathbf{g} \cdot \mathbf{c m}^{-3}\right) \\ \text { RS } & 7.8130 \\ \text { EPS-1 } & 7.7462 \\ \text { EPS-2 } & 7.7686 \\ \text { EPE } & 7.7297 \\ \text { EPP } & 7.7644\end{array}$

Percentage of porosities was calculated according to Equation 1.

$$
\text { Porosity } \%=\left(d_{1}-d_{2}\right) / d_{1}
$$

where $d_{1}$ is equal to true density of alloy which was taken from related ASTM standard $\left(7.82 \mathrm{~g} \cdot \mathrm{cm}^{-3}\right){ }^{[17]}$, and $d_{2}$ is equal to measured density of obtained samples. Results are given in Table 5 with average equivalent diameter values of porosities for each specimen.

According to porosity measurements which are given in Table 5, all the LFC samples exhibited higher porosity rates compared to RS, especially the sample which was produced with EPE, contained the highest porosity amount up to $1.155 \%$ with 3.54 $\mu \mathrm{m}$ average equivalent diameter. On the other hand, EPS-2 exhibited a lower porosity rate among other LFC samples with lower equivalent diameter value near to RS's.

Table 5: Porosity calculations of all samples

\begin{tabular}{ccc|}
\hline RS & 0.090 & $\begin{array}{c}\text { Average equivalent diameter } \\
\text { of porosities }(\mu \mathrm{m})\end{array}$ \\
EPS-1 & 0.944 & 2.83 \\
EPS-2 & 0.657 & 3.14 \\
EPE & 1.155 & 2.94 \\
EPP & 0.711 & 3.54 \\
\hline
\end{tabular}

In Fig. 7, hardness values of all samples after normalization are given. Due to the lower carbon content of green sand mould, cast RS displayed the lowest measured hardness among all specimens with 183.6 HB. LFC samples with different pattern

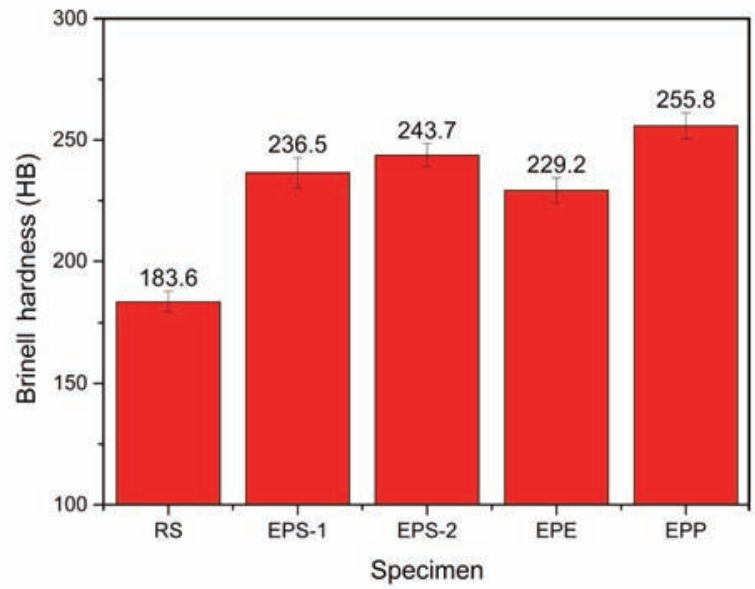

Fig. 7: Brinell hardness values after normalization 
types variated within 229.2 - 255.8 HB with a correlation between their carbon ratios. Increased pearlite amount depending on carbon content of cast products, as reflected by the microstructures, gave rise to increase on hardness values. Maximum hardness value was calculated in the EPP sample as $255.8 \mathrm{HB}$, which was the most carbon-polluted sample.

\section{Conclusions}

In this study, four different types of pattern materials were tested for lost foam casting of A216 Grade WCB low carbon steel. The results of this study led us to the conclusions listed below:

(1) The weight percentage of C content of green sand mould cast samples was 0.214 . According to relevant ASTM standard ${ }^{[17]}$, the $\mathrm{C}$ weight percentage of specified alloy should not exceed 0.3 . However, manufactured specimens with LFC process exceeded the limitations of $\mathrm{C}$ level due to carbon contamination sourced by pattern material except the EPE specimen. EPE was the only one among all the LFC specimens to meet the compositional requirements, but its carbon content was found too close to maximum allowed value for employed alloy.

(2) LFC samples were obtained with lower density due to microporosity areas.

(3) Proportional increase in hardness values was observed for LFC specimens compared to RS depending on carbon content.

(4) No direct relation was found between pattern density and carbon contamination. The densest pattern caused the least amount of carbon contamination among other pattern materials. This situation indicates that the density of polymeric pattern material is not the only parameter for carbon contamination, but the type and the main chain configuration of the polymer may also have effects on carbon pollution during LFC process.

(5) Less dense foam materials yield higher fluidity for molten metal during LFC process ${ }^{[19]}$. However, employing pattern materials with densities too low may cause detrimental effects on overall casting quality as in the case of EPS-1.

(6) Porosity percentage and mean equivalent diameter of porosities were calculated by density calculations and image analysis, respectively. EPE sample displayed the highest porosity with the highest mean equivalent diameter.

(7) Carbon pollution in LFC process differs from surface errors occurring in many common casting methods. Decomposition products of organic pattern materials acted as a carbon source, and diffusion of carbon atoms into cast steel product was found quite serious according to chemical analysis results. This situation created hindrances to obtain desired alloy, which is with a standardized chemical composition. LFC technique is considered as a significant alternative for green sand mould casting method because of its advantages as mentioned in the introduction section. However, this technique was not found suitable for casting of low carbon steel no matter which pattern material was used.

\section{References}

[1] Shroyer H F. Cavityless casting mold and method of making same. United States patent, US 2,830,343, 1958.

[2] Kuo J-H, Chen J-C, Pan Y-N, et al. Mold filling analysis in lost foam casting process for aluminum alloys and its experimental validation. Mater Trans, 2003, 44: 2169-2174.

[3] Kannan P, Biernacki J J, ViscoD P Jr. A review of physical and kinetic models of thermal degradation of expanded polystyrene foam and their application to the lost foam casting process. J Anal Appl Pyrolysis, 2007, 78: 162-171.

[4] Fan Zitian, Jiang Wenming, Liu Fuchu, et al. Status quo and development trend of lost foam casting technology. China Foundry, 2014, 11: 296-307.

[5] Caulk D A . A foam melting model for lost foam casting of aluminium. Int J Heat Mass Transf, 2006, 49: 2124-2136.

[6] Xiao Bo-tao, Fan Zi-tian, Jiang Wen-Ming, et al. Microstructure and mechanical properties of ductile cast iron in lost foam casting with vibration. J Iron Steel Res Int, 2014, 21: 1049-1054.

[7] Shivkumar S, Yao X, Makhlouf M. Polymer-melt interactions during casting formation in the lost foam process. Scr Metall et Mater, 1995, 33: 39-46.

[8] Li Ji-lin, Chen Rong-Shi, Ke Wei. Microstructure and mechanical properties of Mg-Gd-Y-Zr alloy cast by metal mould and lost foam casting. Trans Nonferrous Met Soc China, 2011, 21: 761-766.

[9] Guler KA, Kisasoz A, Karaaslan A. A novel method for Al/SiC composite fabrication: Lost foam casting. Int J Mater Res, 2011, 102: 304-308.

[10] Karimian M, Ourdjini A, Idris $M H$, et al. Effect of pattern coating thickness on characteristics of lost foam Al-Si-Cu alloy casting. Trans Nonferrous Met Soc China, 2012, 22: 2092-2097.

[11] Jiang Wenming, Li Guangyu, Fan Zitian, et al. Investigation on the interface characteristics of $\mathrm{Al} / \mathrm{Mg}$ bimetallic castings processed by lost foam casting. Metall Mater Trans A, 2016, 47: 2462-2470.

[12] Azimi H R, Rezaei M, Abbasi F. Thermo-oxidative degradation of MMASt copolymer and EPS lost foams: Kinetics study. Thermochim Acta, 2009, 488: 43-48.

[13] Jiang Wenming, Fan Zitian, Liu Dejun, et al. Correlation of microstructure with mechanical properties and fracture behavior of A356-T6 aluminum alloy fabricated by expendable pattern shell casting with vacuum and low-pressure, gravity casting and lost foam casting. Mater Sci Eng A, 2012, 560: 396-403.

[14] Pacyniak T, Kaczorowski R. Effect of pouring temperature on the lost foam process. Arch Foundry Eng, 2011, 11: 149-154.

[15] Ainsworth $M \mathrm{~J}$. Metal-foam interface stability during the filling of lost foam moulds with aluminium alloys. Ph.D. Thesis. Birmingham: University of Birmingham, 2010: 3-17.

[16] Rossi M, Camino G, Luda M P. Characterisation of smoke in expanded polystyrene combustion. Polym Degrad Stab, 2001, 74: 507-512.

[17] American Society for Testing and Materials (ASTM) Standard No: A216/ A216M-16, Standard Specification for Steel Castings, Carbon, Suitable for Fusion Welding, for High-Temperature Service; 2016.

[18] Beyler C L, Hirschler M M. SFPE handbook of fire protection engineering, 3rd ed., Massachusetts (USA): National Fire Protection Association, Section 1, Chapter 7, Thermal decomposition of polymers. 2002: 110-131.

[19] Pacyniak T. Effect of foamed pattern density on the lost foam process. Arch Foundry Eng, 2007, 7: 231-236.

\section{Acknowledgements:}

We present our gratitude to AKMETAL Metallurgical Industries Corp. managers and all employees. We especially thank Eylem SUBASI, who did not refrain her material and spiritual support during the casting processes involved in this work. 